\title{
A Systematic Review of Clinical Diagnostic Systems Used in the Diagnosis of Tuberculosis in Children
}

\author{
Emily C. Pearce, ${ }^{1}$ Jason F. Woodward, ${ }^{1}$ Winstone M. Nyandiko, ${ }^{2}$ \\ Rachel C. Vreeman, ${ }^{1}$ and Samuel O. Ayaya ${ }^{2}$ \\ ${ }^{1}$ Department of Pediatrics, Indiana University School of Medicine, Indianapolis, IN 46202, USA \\ ${ }^{2}$ Department of Pediatrics, Moi University School of Medicine, Eldoret 30100, Kenya \\ Correspondence should be addressed to Emily C. Pearce, ecpearce@gmail.com
}

Received 28 March 2012; Accepted 9 May 2012

Academic Editor: Amneris Luque

Copyright (C) 2012 Emily C. Pearce et al. This is an open access article distributed under the Creative Commons Attribution License, which permits unrestricted use, distribution, and reproduction in any medium, provided the original work is properly cited.

\begin{abstract}
Background. Tuberculosis (TB) is difficult to diagnose in children due to lack of a gold standard, especially in resource-limited settings. Scoring systems and diagnostic criteria are often used to assist in diagnosis; however their validity, especially in areas with high HIV prevalence, remains unclear. Methods. We searched online bibliographic databases, including MEDLINE and EMBASE. We selected all studies involving scoring systems or diagnostic criteria used to aid in the diagnosis of tuberculosis in children and extracted data from these studies. Results. The search yielded 2261 titles, of which 40 met selection criteria. Eighteen studies used point-based scoring systems. Eighteen studies used diagnostic criteria. Validation of these scoring systems yielded varying sensitivities as gold standards used ranged widely. Four studies evaluated and compared multiple scoring criteria. Ten studies selected for pulmonary tuberculosis. Five studies specifically evaluated the use of scoring systems in HIV-positive children, generally finding the specificity to be lower. Conclusions. Though scoring systems and diagnostic criteria remain widely used in the diagnosis of tuberculosis in children, validation has been difficult due to lack of an established and accessible gold standard. Estimates of sensitivity and specificity vary widely, especially in populations with high HIV co-infection.
\end{abstract}

\section{Background}

Tuberculosis (TB) remains one of the most important causes of pediatric mortality worldwide, especially in areas with high HIV prevalence. There are approximately nine million new TB cases each year, with ten percent of those occurring in children, equaling almost one million new pediatric cases each year. Seventy-five percent of those are in twentytwo high-burden countries, which also tend to have fewer resources for diagnosis. Accurate and timely diagnosis of pediatric TB remains crucial because children are more likely than adults to progress from latent infection to active $\mathrm{TB}$ disease [1].

One of the largest challenges in preventing morbidity and mortality from TB among the pediatric population is the difficulty in making a timely diagnosis. Diagnostic approaches relying on symptoms, chest radiographs, tuberculin skin tests, or cultures all have particular challenges within the pediatric population. TB symptoms vary and overlap with other common pediatric diseases, especially in children who are coinfected with TB and HIV. Cough, anorexia, and weight loss are common in TB but nonspecific and might lead to overdiagnosis if used alone [2].

Chest radiography also is difficult to interpret in pediatric patients, who are less likely to have cavitations or clear radiological signs of TB. Mediastinal lymphadenopathy is often regarded as a radiologic hallmark of primary TB; however, this is difficult to diagnose on a plain chest Xray (CXR), which may be of variable quality, particularly in some resource-limited settings. Also, significant interobserver variation exists when interpreting pediatric CXR for TB diagnosis [3].

Previous studies have shown various utility in using the tuberculin skin test (TST) in a highly BCG vaccinated population due to a concern for a high rate of false positives [4]. Though some evidence has shown that BCG-vaccinated 
children with known exposure to TB have a higher rate of positive tests than community controls [5], this study did not address the utility in other populations where TST may not be as sensitive, such as HIV-infected or malnourished children.

Pediatric TB tends to be pauci-bacillary and thus it is also more difficult to diagnose using cultures, especially in children who are too young to provide sputum [1]. Attempts have been made to improve the utility of culture-proven diagnosis by using induced sputum samples or gastric aspirates. These samples can still be difficult to obtain in children. Moreover, conducting these procedures in resource-limited settings can be difficult [6]. Because of the challenges in diagnosing pediatric TB through individual clinical signs and symptoms, radiological studies, or laboratory examinations, point-based scoring systems or diagnostic criteria are often used to assist in the diagnosis of TB in children.

The first major point-based scoring system was introduced by Stegen et al. in Chile in 1969 [7] and has continued to be modified and used around the world through the present [8-14]. The Keith Edwards criteria were originally published in 1987 [15] and also have been widely used [1619] outside the original location of Papua New Guinea. Of the many diagnostic systems developed, the World Health Organization (WHO) criteria, originally published in 1983, are the most widely used [20]. The major objective of all of the diagnostic systems is to provide a consistent and accurate way to diagnose pediatric TB, especially in resource-limited settings.

Although these scoring systems and diagnostic criteria are commonly used [21], their reliability and validity remain unclear. Different diagnostic criteria are used in different settings, and they may or may not have been validated for those locations. Moreover, the challenges of using these criteria in settings where many of the children are malnourished or coinfected with HIV have not been fully examined. Many of the diagnostic systems were developed prior to the onset of the HIV epidemic and may not perform adequately in children with coinfection. Since TB is a leading cause of mortality among the world's 2.3 million HIV-infected children, diagnosing TB among coinfected children is a particularly important challenge and may require significant adaptations of current diagnostic systems [22].

Prevention of childhood morbidity and mortality due to $\mathrm{TB}$ requires accurate and timely diagnosis. A previous systematic review of pediatric TB diagnostic strategies, published in 2002, recommended standardization of definitions and characteristics, pointing out the need for new diagnostic approaches [21]. Since that review, at least twenty-one new papers on pediatric TB diagnosis have been published, including several highlighting new strategies such as the Brazil Ministry of Health system [23-25] and the Marais criteria [26]. In addition, the population of children living with HIV infection has reached 2.3 million, simultaneously expanding the numbers of children vulnerable to TB disease [22]. This systematic review seeks to systematically identify, review, and compare various methods of diagnosis of $\mathrm{TB}$ in children in order to inform clinical practice and future research in this area. It aims to organize the scoring systems and diagnostic criteria based on their common components, critically analyze the extent to which the criteria are validated, and highlight those that have focused specifically on children that are coinfected with HIV and TB.

\section{Methods}

We searched several bibliographic databases, including MEDLINE (through October 19, 2009), EMBASE, and relevant websites such as those for the World Health Organization. We used the following strategy: (tuberculosis/diagnosis) [MeSH heading] AND (criteria* OR screen* OR guideline* OR scor*). Three authors (S. O. Ayaya, J. F. Woodward, and E. C. Pearce) reviewed all returned titles and excluded articles that obviously did not involve children or tuberculosis. These authors then reviewed abstracts of remaining articles to determine which studies examined scoring systems or diagnostic criteria used in the diagnosis of pediatric tuberculosis. The bibliographies of all relevant articles were also reviewed for potential articles.

Two investigators (J. F. Woodward and E. C. Pearce) independently reviewed the remaining articles, independently deciding on inclusion in the review using a standard form with predetermined eligibility criteria. Disagreements were resolved by consensus. For inclusion, the articles needed to describe a descriptive or interventional study involving the use of a clinical diagnostic system to diagnose tuberculosis in pediatric patients. Only English language articles were included. Pediatric patients were described as individuals less than 18 years of age. Clinical diagnostic systems included both scoring systems and diagnostic criteria. Scoring systems were defined as point-based criteria with set numerical cutoffs for a positive diagnosis. Diagnostic criteria were defined as nonpoint-based systems in which a certain number of criteria out of the total or out of each group were needed for diagnosis. Studies analyzing the diagnosis of pediatric tuberculosis in general without using or evaluating a particular scoring system or diagnostic criteria were used as background information only for the review. Each article was analyzed to determine the study setting, study design and methods, sample characteristics, type of diagnostic system used, reference or gold standard used for comparison, and efforts at validation of the diagnostic system. We excluded duplicate publications of the same findings.

\section{Results}

The systematic literature search identified 2261 articles. The online search of MEDLINE yielded 2011 articles, and the search of EMBASE yielded 250 articles, many of which were also found by the MEDLINE search. Additional potential studies were identified through searches of bibliographies. After articles that did not address the diagnosis of tuberculosis in children were excluded, 408 articles remained. Further articles were excluded upon closer review because they did not include pediatric patients, did not include a scoring system or diagnostic criteria, or focused only on screening for latent tuberculosis. Articles that briefly mentioned a scoring 
TABLE 1: Point-based scoring systems and studies evaluating these systems.

\begin{tabular}{|c|c|c|c|c|c|}
\hline Author & Year & Country & Scoring criteria & Changes & Study type \\
\hline Stegen et al. [7] & 1969 & Chile & Kenneth Jones & New & Review with case reports \\
\hline Mathur et al. [9] & 1974 & India & Kenneth Jones & Added marasmus to original criteria & Prospective observational \\
\hline Nair and Philip [10] & 1981 & India & Kenneth Jones & $\begin{array}{l}\text { Changed point values, took away } \\
\text { negative points for BCG, added re- } \\
\text { sponse to treatment }\end{array}$ & Prospective \\
\hline Seth [11] & 1991 & India & Kenneth Jones & Used Nair's adaptation & Book excerpt \\
\hline Shah et al. [12] & 1992 & India & Kenneth Jones & $\begin{array}{l}\text { Added history of measles/whooping } \\
\text { cough }\end{array}$ & Prospective observational \\
\hline Mehnaz and Arif [13] & 2005 & Pakistan & Kenneth Jones & $\begin{array}{l}\text { Modified multiple criteria, added } \\
\text { and subtracted criteria }\end{array}$ & Retrospective case control \\
\hline Oberhelmen et al. [14] & 2006 & Peru & Stegen-Toledo & No modifications & Prospective observational \\
\hline Viani et al. [8] & 2008 & Mexico & Stegen-Toledo & Added points for positive stain & Retrospective chart review \\
\hline Edwards [15] & 1987 & $\begin{array}{l}\text { Papau New } \\
\text { Guinea }\end{array}$ & Keith Edwards & Original & Review article \\
\hline van Beekhuizen [16] & 1998 & $\begin{array}{l}\text { Papua New } \\
\text { Guinea }\end{array}$ & Keith Edwards & No modifications & Prospective observational \\
\hline Weismuller et al. [17] & 2002 & Malawi & $\begin{array}{l}\text { WHO score } \\
\text { chart (modified } \\
\text { Keith Edwards) }\end{array}$ & $\begin{array}{l}\text { Added no response to malaria treat- } \\
\text { ment, modified language }\end{array}$ & $\begin{array}{l}\text { Cross-sectional } \\
\text { observational study }\end{array}$ \\
\hline van Rheenen [18] & 2002 & Zambia & Keith Edwards & Modified language & Prospective cohort \\
\hline Narayan et al. [19] & 2003 & India & Keith Edwards & $\begin{array}{l}\text { Added no response to malaria treat- } \\
\text { ment }\end{array}$ & Prospective observational \\
\hline Sant'Anna et al. [24] & 2006 & Brazil & $\begin{array}{l}\text { Brazil Ministry } \\
\text { of Health }\end{array}$ & New & Retrospective case control \\
\hline Sant'Anna et al. [25] & 2004 & Brazil & $\begin{array}{l}\text { Brazil Ministry } \\
\text { of Health }\end{array}$ & No modifications & Retrospective \\
\hline Pedrozo et al. [23] & 2009 & Brazil & $\begin{array}{l}\text { Brazil Ministry } \\
\text { of Health }\end{array}$ & No modifications & Prospective observational \\
\hline Fourie et al. [27] & 1998 & Multiple & New & $\begin{array}{l}\text { Set up new scoring criteria by con- } \\
\text { sensus decision }\end{array}$ & Retrospective \\
\hline Bergman [28] & 1995 & Zimbabwe & New & New & Review \\
\hline
\end{tabular}

system but did not give details or include how it was used in the study were also excluded. Forty articles met the general study criteria.

3.1. Clinical Diagnostic Systems Used for TB Diagnosis. From the forty articles that included a clinical diagnostic system, we extracted information on the setting, location, sample size, type of system/criteria used, efforts at validation, choice of gold standard, and the effect of HIV coinfection in the population. The characteristics of these studies, including the validation strategies, are summarized in Tables 1, 2, and 3. Eighteen studies used scoring systems; these studies could be further divided into five groups based on a common initial system modified by different authors (Table 1). The three major groups were the following: (1) the Kenneth
Jones/Stegen-Toledo system [7-14]; (2) the Keith Edwards system [15-19]; (3) the Brazil Ministry of Health $(\mathrm{MOH})$ system [23-25]. Fourie et al. [27] and Bergman [28] also presented new systems without further published studies. Eighteen studies used diagnostic criteria. These studies could be further divided into five groups of diagnostic criteria presented by Ghidey and Habte [29], Migliori et al. [30], Mahdi et al. [31], Salazar et al. [32], Marais et al. [26], the WHO guidelines [33-42], Osborne [43], Jeena et al. [44], and Ramachandran [45] (Table 2). Four articles compared two or more scoring criteria [46-49] (Table 3).

3.2. Validation of Clinical Diagnostic Systems for Pediatric TB Diagnosis. Of the above forty articles, sixteen attempted to validate the diagnostic system or systems (Table 4). Gold 
TABle 2: Diagnostic classifications and studies evaluating these classifications.

\begin{tabular}{|c|c|c|c|c|c|}
\hline Author & Year & Country & Scoring criteria & Changes & Study type \\
\hline $\begin{array}{l}\text { Ghidey and Habte } \\
\text { [29] }\end{array}$ & 1983 & Ethiopia & New & New & Prospective \\
\hline Migliori et al. [30] & 1992 & Uganda & $\begin{array}{l}\text { Migliori-revised from Ghidey } \\
\text { and Habte }\end{array}$ & $\begin{array}{l}\text { Focused towards PTB, added re- } \\
\text { sponse to treatment as a criteria }\end{array}$ & Prospective \\
\hline Madhi et al. [31] & 1999 & South Africa & Migliori & No change & Prospective \\
\hline Salazar et al. [32] & 2001 & Peru & Migliori & $\begin{array}{l}\text { Removed response to treatment. } \\
\text { Created Peru criteria. }\end{array}$ & $\begin{array}{l}\text { Prospective } \\
\text { cohort }\end{array}$ \\
\hline Marais et al. [26] & 2006 & South Africa & New & Symptom based approach & Prospective \\
\hline $\begin{array}{l}\text { World Health } \\
\text { Organization [20] }\end{array}$ & 1983 & Multiple & New & New & New guidelines \\
\hline Cundall [33] & 1986 & Kenya & 1983 WHO guidelines & Modifies by adding family contact & Prospective \\
\hline Stoltz et al. [34] & 1990 & South Africa & Modified 1983 WHO guidelines & No change & Prospective \\
\hline Beyers et al. [35] & 1994 & South Africa & 1983 WHO guidelines & No change & Prospective \\
\hline Gie et al. [36] & 1995 & South Africa & Modified 1983 WHO guidelines & No change & Prospective \\
\hline Schaaf et al. [37] & 1995 & South Africa & 1983 WHO guidelines & No change & Prospective \\
\hline $\begin{array}{l}\text { Houwert et al. } \\
\text { [38] }\end{array}$ & 1998 & South Africa & 1994 WHO guidelines & No change & Prospective \\
\hline $\begin{array}{l}\text { Kiwanuka et al. } \\
{[42]}\end{array}$ & 2001 & Malawi & 1983 WHO guidelines & $\begin{array}{l}\text { Modified by using only certain radi- } \\
\text { ological findings or positive TST for } \\
\text { probable TB }\end{array}$ & Prospective \\
\hline Palme et al. [39] & 2002 & Ethiopia & Modified 1983 WHO guidelines & Required $2 / 6$ criteria & $\begin{array}{l}\text { Prospective } \\
\text { case-control }\end{array}$ \\
\hline Theart et al. [40] & 2005 & South Africa & Modified 1983 WHO guidelines & No change & Retrospective \\
\hline Cohen et al. [41] & 2008 & UK & 2006 WHO classification & No change & Retrospective \\
\hline Osborne [43] & 1995 & Zambia & Lusaka's UTH Criteria & New & Review article \\
\hline Jeena et al. [44] & 1996 & South Africa & Lusaka's UTH criteria & No change & Prospective \\
\hline $\begin{array}{l}\text { Ramachandran } \\
{[45]}\end{array}$ & 1968 & India & New & New & $\begin{array}{l}\text { Prospective and } \\
\text { retrospective }\end{array}$ \\
\hline
\end{tabular}

TABLE 3: Studies evaluating and comparing multiple diagnostic systems.

\begin{tabular}{llll}
\hline Author & Year Country & Findings \\
\hline $\begin{array}{l}\text { Hesseling et al. } \\
{[21]}\end{array}$ & 2002 South Africa & $\begin{array}{l}\text { Analyzed } 16 \text { diagnostic systems, specifically looks at how systems have been adapted for HIV- } \\
\text { infected and malnourished patients. } \\
\text { Analyzed } 8 \text { scoring systems, found correlation to be poor to moderate. Decision to initiate } \\
\text { treatment for TB was dependent on scoring system used in 14\% of children. Selection had a } \\
\text { greater impact in HIV-infected patients. }\end{array}$ \\
$\begin{array}{l}\text { Edw } \\
\text { Ahmed et al. }\end{array}$ & 2007 Congo & Bangladesh & $\begin{array}{l}\text { Reviews previous scoring systems as well as Hesseling et al. [21] and Edwards et al. [47] } \\
{[48]}\end{array}$ \\
$\begin{array}{l}\text { Raqib et al. } \\
{[49]}\end{array}$ & 2009 Bangladesh & $\begin{array}{l}\text { Analyzed a new diagnostic test (ALS assay) detecting antibodies secreted from circulating MTB- } \\
\text { specific plasma cells in comparison to the Kenneth Jones and WHO/Keith Edwards scoring } \\
\text { criteria as well as clinical diagnosis. }\end{array}$ \\
\hline
\end{tabular}


TABLE 4: Studies attempting validation of diagnostic systems.

\begin{tabular}{|c|c|c|c|c|c|}
\hline Author & Year & Country & Scoring criteria & Validation & Gold standard \\
\hline \multicolumn{6}{|c|}{ Point-based scoring systems } \\
\hline Mathur et al. [9] & 1974 & India & Kenneth Jones & $\begin{array}{l}\text { Sens } 73 \% \quad \text { (original criteria) } \\
\text { Sens } 95 \% \text { (modified criteria) }\end{array}$ & Clinical diagnosis \\
\hline Shah et al. [12] & 1992 & India & Kenneth Jones & $\begin{array}{l}\text { Compared modified criteria to pre- } \\
\text { vious Kenneth Jones }\end{array}$ & Previous KJ \\
\hline $\begin{array}{l}\text { Mehnaz and Arif } \\
{[13]}\end{array}$ & 2005 & Pakistan & Kenneth Jones & Retrospective analysis & $\begin{array}{l}\text { Clinical control and response to } \\
\text { treatment }\end{array}$ \\
\hline Viani et al. [8] & 2008 & Mexico & Stegen-Toledo & Retrospective analysis & Clinical diagnosis \\
\hline $\begin{array}{l}\text { van Beekhuizen } \\
\text { [16] }\end{array}$ & 1998 & $\begin{array}{l}\text { Papua New } \\
\text { Guinea }\end{array}$ & Keith Edwards & Sens $62 \%$, spec $95 \%$ & $\begin{array}{l}\text { Improvement on anti-TB treat- } \\
\text { ment or positive CXR }\end{array}$ \\
\hline $\begin{array}{l}\text { Weismuller et al. } \\
{[17]}\end{array}$ & 2002 & Malawi & $\begin{array}{l}\text { WHO score } \\
\text { chart (modified } \\
\text { Keith Edwards) }\end{array}$ & $\begin{array}{l}\text { Sens } 61 \% \text { for all types of TB; } 54 \% \text { for } \\
\text { PTB and } 73 \% \text { for EPTB }\end{array}$ & $\begin{array}{l}\text { Clinical diagnosis-differed by } \\
\text { various hospitals }\end{array}$ \\
\hline van Rheenen [18] & 2002 & Zambia & Keith Edwards & $\begin{array}{l}\text { Sens } 88 \% \text {, spec } 25 \% \text {, PPV } 55 \% \text {, } \\
\text { NPV } 67 \%\end{array}$ & Diagnostic algorithm \\
\hline Narayan et al. [19] & 2003 & India & Keith Edwards & Sens $91 \%$, spec $88 \%$ & Clinical diagnosis \\
\hline $\begin{array}{l}\text { Sant'Anna et al. } \\
{[24]}\end{array}$ & 2006 & Brazil & $\begin{array}{l}\text { Brazil Ministry } \\
\text { of Health }\end{array}$ & Sens $89 \%$, spec $86 \%$ & $\begin{array}{l}\text { Culture positive and respiratory } \\
\text { symptoms and/or CXR improved } \\
\text { using exclusively anti-TB drugs }\end{array}$ \\
\hline $\begin{array}{l}\text { Sant'Anna et al. } \\
{[25]}\end{array}$ & 2004 & Brazil & $\begin{array}{l}\text { Brazil Ministry } \\
\text { of Health }\end{array}$ & $\begin{array}{l}82 \% \text { very likely, } 16 \% \text { possible, } 2.4 \% \\
\text { unlikely }\end{array}$ & $\begin{array}{l}\text { Clinical criteria and response to } \\
\text { treatment }\end{array}$ \\
\hline Pedrozo et al. [23] & 2009 & Brazil & $\begin{array}{l}\text { Brazil Ministry } \\
\text { of Health }\end{array}$ & $\begin{array}{l}\text { Median score of } \mathrm{TB} \text { positive groups } \\
\text { higher than negative }\end{array}$ & Clinical criteria \\
\hline Fourie et al. [27] & 1998 & Multiple & New & $\begin{array}{l}\text { Analyzed by age and country group: } \\
\text { sens } 30-73 \% \text {, spec } 10-75 \% \text {, PPV } \\
50-82 \%\end{array}$ & $\begin{array}{l}\text { Positive radiologic or bacterio- } \\
\text { logical data }\end{array}$ \\
\hline
\end{tabular}

Diagnostic classification

\begin{tabular}{|c|c|c|c|c|c|}
\hline Migliori et al. [30] & 1992 & Uganda & Migliori & $\begin{array}{l}\text { Gastric aspirate: sens } 96.8 \% \text {, spec } \\
92.2 \% \text {, PPV } 68.2 \% \text {, NPV } 99.4 \% \text {. } \\
\text { Response to treatment: sens } 62.5 \% \text {, } \\
94.1 \% \text {, PPV } 57.7 \% \text {, NPV } 95.1 \%\end{array}$ & $\begin{array}{l}\text { Original Ghidey and Habte crite- } \\
\text { ria }\end{array}$ \\
\hline Salazar et al. [32] & 2001 & Peru & Migliori & $\begin{array}{l}\text { Sens } 92 \% \text { (Migliori) versus } 80 \% \\
\text { (Peru). } 3 / 3 \text { Peru criteria had } 73 \% \\
\text { PPV }\end{array}$ & Migliori criteria (without RTT) \\
\hline Marais et al. [26] & 2006 & South Africa & New & $\begin{array}{l}\text { Children } \geq 3 \text { and HIV uninfected: } \\
\text { sens } 82.3 \% \text {, spec } 90.2 \% \text {, PPV } 82.3 \% \text {. } \\
\text { Children <3 and HIV uninfected: } \\
\text { sens } 51.8 \% \text {, spec } 92.5 \% \text {, PPV } 90.1 \% \text {. } \\
\text { HIV infected: sens } 56.2 \% \text {, spec } \\
61.8 \% \text {, PPV } 61.9 \%\end{array}$ & Clinical criteria \\
\hline Houwert et al. [38] & 1998 & South Africa & $\begin{array}{l}\text { WHO } \\
\text { provisional } \\
\text { guidelines } \\
(1994)\end{array}$ & $\begin{array}{l}\text { PPV of all } 3 \text { criteria when present } \\
\text { simultaneously: } 63 \%\end{array}$ & $\begin{array}{l}\text { WHO diagnostic categories from } \\
1994 \text { used as the gold standard }\end{array}$ \\
\hline
\end{tabular}

Sens: sensitivity; spec: specificity; PTB: pulmonary tuberculosis; EPTB: extrapulmonary tuberculosis; PPV: positive predictive value; NPV: negative predictive value. 
standards used in validation varied greatly and ranged from positive cultures to clinical diagnosis to previous scoring criteria. The only study using cultures as the primary gold standard was Sant'Anna et al. [24], which found a sensitivity of $89 \%$ and specificity of $86 \%$ when evaluating Brazil Ministry of Health criteria against a standard of culturepositive patients. Sant'Anna et al. [25] also performed a retrospective analysis on a different study population using clinical consensus as the gold standard against which to compare the diagnostic criteria, resulting in similar sensitivity.

Culture for Mycobacterium tuberculosis is less sensitive in pediatric patients and difficult to obtain in resource-limited settings; therefore, the most common gold standard used to validate diagnostic systems was clinical diagnosis. The definition of clinical diagnosis varied widely between studies and was often not defined in detail. Because many of the studies were retrospective, clinical diagnosis was often simply defined as children who had been admitted with a diagnosis of TB $[8,34]$, with some studies also specifying that the children must have improved on anti-TB medication [13, 40, 41]. In one article, the study population was drawn from forty-four different hospitals, all of which used their own methods of clinical diagnosis [17]. However, in other studies, the method of clinical diagnosis was explained in depth. For example, van Rheenen described a detailed algorithm that included clinical findings, culture, CXR, TST, contact history, and response to treatment [18].

Previously described scoring criteria were also used as a gold standard; a few of the studies compared their modifications of a certain diagnostic system to the original. For example, Migliori et al. modify the criteria published by Ghidey and Habte [29] by focusing the criteria on pulmonary $\mathrm{TB}$ and adding response to treatment and use the original criteria as the gold standard in their analysis [30]. Salazar et al. then modified the Migliori criteria to develop the Peru criteria, and used the original Migliori criteria as the gold standard for comparison [32]. These are not traditional validation strategies as they assume the previous criteria have been validated to an extent that they may now be considered a gold standard in themselves.

Four published papers evaluated and compared multiple scoring systems and diagnostic criteria (Table 3). In a 2002 systematic review, Hesseling et al. stressed the need for standardization of definitions and point values between the various algorithms [21]. As an update on Hesseling's review, this current review includes twenty-one new studies, including those evaluating the Brazil MOH scoring system [23-25] and the Marais criteria [26]. In 2008, Ahmed et al. published a review of TB diagnosis as well as treatment, focusing mainly on the Kenneth Jones and Keith Edwards systems [48] and suggesting the need for further research. Most recently, in 2009, Raquib et al. compared a newer diagnostic test (ALS assay) to clinical diagnosis, the Kenneth Jones, and the Keith Edwards scoring criteria [49], finding that sensitivity, specificity, and overall concordance was higher when the ALS assay was compared to clinical diagnosis than to the scoring criteria.

In a 2007 article, Edwards et al. used data from a retrospective review of $\mathrm{TB}$ cases at a pediatric hospital with a highprevalence of HIV infection to calculate scores for eight diagnostic scoring systems [47]. The decision to initiate treatment for $\mathrm{TB}$ was dependent on the scoring system used, with at least one scoring system recommending not to treat for $14 \%$ of the children studied. Except for the systems derived from a common original diagnostic system, correlation was poor to moderate for agreement of when to initiate treatment based on the various scoring systems.

3.3. Variation among Criteria. Although all of the scoring criteria have aspects in common, their purposes and specifics have varied over the past 40 years since Stegen et al. published the original Kenneth Jones criteria. The Kenneth Jones criteria include laboratory tests but exclude clinical criteria such as cough and fever due to concerns that they would lower the specificity [7]. In contrast, the purpose of the Keith Edwards criteria was focused towards a completely clinical diagnosis, and thus excluded laboratory data except for a TST [15].

Both the Kenneth Jones and Keith Edwards criteria were designed for the diagnosis of both pulmonary and extrapulmonary tuberculosis. Because the clinical signs and symptoms of extrapulmonary tuberculosis may differ from those of pulmonary tuberculosis, several studies evaluated the ability of diagnostic strategies to identify pulmonary $\mathrm{TB}$ specifically (Table 5). For example, the Brazil $\mathrm{MOH}$ system, designed specifically for pulmonary tuberculosis [24, 25], has shown a sensitivity of $89 \%$ and a specificity of $86 \%$. The Migliori [30] and Marais [26] diagnostic criteria, also focused on pulmonary tuberculosis, demonstrated a sensitivity of $92 \%$ [31] and $82 \%$, respectively. While the Migliori criteria have not been tested in children with coinfection, the sensitivity of the Marais criteria decreased to $51-56 \%$ when children under three years of age and HIV infected children were included [26].

A salient difference between the various clinical diagnostic approaches was the choice of included criteria. The criteria included most commonly were the tuberculin skin test (TST) and positive history of TB contact; however, the definition of these criteria was not standardized. For example, the definition of a positive TST varies widely among studies [7, 15]. A positive history of TB contact also was defined in various ways, such as requiring confirmed sputum-positive contact [37] or only a self-report of contact [30]. In some cases, the history of contact had to be within the past two years [14]. Using both the TST and the positive contact history may also be redundant if both are included. Variability is also seen in the other criteria, such as clinical symptoms and CXR. The various definitions and subjectivity of many of the criteria included in the diagnostic approaches make it difficult to compare the diagnostic strategies and the attempts at validation. In addition, clinicians likely vary in how they implement the scoring criteria, thus, making the diagnostic thresholds even less consistent.

3.4. Clinical Diagnostic Systems in HIV-Infected Patients. A few studies specifically examined TB diagnosis in HIVinfected children (Table 6). In his comparison of eight 
TABLe 5: Studies focusing primarily on pulmonary tuberculosis.

\begin{tabular}{|c|c|c|c|c|c|}
\hline Author & Year & Country & Scoring system & Percent also with EPTB & Validation \\
\hline Shah et al. [12] & 1992 & India & $\begin{array}{l}\text { Modified } \\
\text { Kenneth Jones }\end{array}$ & $\begin{array}{l}\text { Looked at "primary complex" } \\
\text { (just pulmonary) versus "pro- } \\
\text { gressive primary complex" (pul- } \\
\text { monary plus LAD) }\end{array}$ & $\begin{array}{l}\text { Not analyzed, just used in inclu- } \\
\text { sion criteria }\end{array}$ \\
\hline
\end{tabular}

Migliori et al. [30] 1992 Uganda Migliori All pulmonary

Gastric aspirate: sens $96.8 \%$, spec $92.2 \%$, PPV 68.2\%, NPV 99.4\%. Response to treatment: sens $62.5 \%, 94.1 \%$, PPV $57.7 \%$, NPV $95.1 \%$

\begin{tabular}{|c|c|c|c|c|c|}
\hline Beyers et al. [35] & 1994 & South Africa & $\begin{array}{l}\text { Modified } 1883 \\
\text { WHO criteria }\end{array}$ & $\begin{array}{l}\text { All pulmonary-excluded extra- } \\
\text { pulmonary tuberculosis without } \\
\text { lung involvement }\end{array}$ & Not evaluated \\
\hline Salazar et al. [32] & 2001 & Peru & Migliori & $\begin{array}{l}\text { All pts had PTB, } 21 / 135 \text { had } \\
\text { EPTB as well: lymphadenopa- } \\
\text { thy, intestinal-intraperitoneal TB, } \\
\text { intra-abdominal lymphadenopa- } \\
\text { thy, miliary disease, meningitis, } \\
\text { and optic involvement. } 3 \text { with } \\
\text { EPTB did not meet criteria for } \\
\text { PTB }\end{array}$ & $\begin{array}{l}\text { Sens } 92 \% \text { (Migliori) versus } 80 \% \\
\text { (Peru). } 3 / 3 \text { Peru criteria had } 73 \% \\
\text { PPV }\end{array}$ \\
\hline Sant'Anna et al. [25] & 2004 & Brazil & $\begin{array}{l}\text { Brazil Ministry } \\
\text { of Health }\end{array}$ & $\begin{array}{l}82 \% \text { very likely, } 16 \% \text { possible, } \\
2.4 \% \text { unlikely }\end{array}$ & $\begin{array}{l}\text { All pulmonary plus } 5 \text { pts with } \\
\text { assoc extrapulmonary TB }\end{array}$ \\
\hline Sant'Anna et al. [24] & 2006 & Brazil & $\begin{array}{l}\text { Brazil Ministry } \\
\text { of Health }\end{array}$ & $\begin{array}{l}\text { Cut off } \geq 40 \text { : sens } 58 \% \text { and spec } \\
98 \% \text { but missed } 42 \% \text { of con- } \\
\text { firmed PTB. } \\
\text { Cut off } \geq 30 \text { : sens } 89 \% \text { and spec } \\
86 \%\end{array}$ & Pulmonary \\
\hline Oberhelmen et al. [14] & 2006 & Peru & Stegen-Toledo & $\begin{array}{l}\text { Not analyzed, just used in inclu- } \\
\text { sion criteria }\end{array}$ & Pulmonary \\
\hline Marais et al. [26] & 2006 & South Africa & New & $\begin{array}{l}\text { Children } \geq 3 \text { and HIV uninfected: } \\
\text { sens } 82.3 \% \text {, spec } 90.2 \%, \text { PPV } \\
82.3 \% \text {. } \\
\text { Children }<3 \text { and HIV uninfected: } \\
\text { sens } 51.8 \% \text {, spec } 92.5 \%, \text { PPV } \\
90.1 \% \text {. HIV infected: sens } 56.2 \% \text {, } \\
\text { spec } 61.8 \% \text {, PPV } 61.9 \%\end{array}$ & Focused on pulmonary TB only \\
\hline Viani et al. [8] & 2008 & Mexico & Stegen-Toledo & $\begin{array}{l}\text { Looked retrospectively: } 10 / 13 \\
\text { highly probable, } 2 / 13 \text { probable, } \\
1 / 13 \text { suspicious }\end{array}$ & $\begin{array}{l}100 \% \text { pulmonary, } 54 \% \text { also had } \\
\text { disseminated }\end{array}$ \\
\hline Pedrozo et al. [23] & 2009 & Brazil & $\begin{array}{l}\text { Brazil Ministry } \\
\text { of Health }\end{array}$ & $\begin{array}{l}\text { Analyzed scoring system by look- } \\
\text { ing at median scores of vari- } \\
\text { ous groups: median score of } 3 a \\
\text { and } 3 \text { b sig. higher than } 1 \text { and } \\
2 \text {, median score also was higher } \\
\text { than the cut off of } 30\end{array}$ & Pulmonary only \\
\hline
\end{tabular}

Sens: sensitivity; spec: specificity; PTB: pulmonary tuberculosis; EPTB: extrapulmonary tuberculosis; PPV: positive predictive value; NPV: negative predictive value.

diagnostic scoring systems, Edwards showed that HIVinfected children tended to have higher scores, especially when the Keith Edwards system was used, leading to a concern for over-diagnosis of TB in HIV-infected children [47]. Marais et al. found that the Marais diagnostic criteria were less sensitive (56\% compared to $82 \%$ ) and less specific (62\% compared to $90 \%$ ) when evaluating children with HIV as opposed to children without HIV. The positive predictive value also decreased to $62 \%$ in HIV-infected children as compared to $82 \%$ in children without HIV [26]. Viani et al. looked at a small cohort of coinfected children in Mexico retrospectively and found that $77 \%$ had scores indicating highly probable TB when using the Stegen-Toledo criteria [8]. Finally, in a 2009 analysis of the Brazil MOH criteria, Pedrozo et al. found that while coinfected children did score slightly lower than HIV-uninfected children, their scores were still significantly higher than children without $\mathrm{TB}$ [25]. 
TABLE 6: Studies that specified how many patients were coinfected with HIV.

\begin{tabular}{|c|c|c|c|c|c|}
\hline Author & Year & Country & Total patients & Percent HIV positive & Findings \\
\hline Madhi et al. [31] & 1999 & South Africa & 130 & $40 \%$ & $\begin{array}{l}\text { Did not attempt to validate scoring crite- } \\
\text { ria }\end{array}$ \\
\hline Kiwanuka et al. [42] & 2001 & Malawi & 110 & $71 \%$ (of 102 tested) & $\begin{array}{l}\text { Did not attempt to validate scoring crite- } \\
\text { ria }\end{array}$ \\
\hline Palme et al. [39] & 2002 & Ethiopia & 517 & $11.2 \%$ & $\begin{array}{l}\text { Did not attempt to validate scoring crite- } \\
\text { ria }\end{array}$ \\
\hline van Rheenen [18] & 2002 & Zambia & 147 & $30 \%$ & $\begin{array}{l}\text { Keith Edwards scoring system: sensitivity } \\
88 \% \text { and specificity } 25 \% \text { in this study. } \\
\text { Most of the children with a false positive } \\
\text { score were malnourished }(48 \%) \text { or had } \\
\text { AIDS }(31 \%)\end{array}$ \\
\hline Marais et al. [26] & 2006 & South Africa & 428 & $8.8 \%$ & $\begin{array}{l}\text { Sensitivity, specificity, and PPV all de- } \\
\text { creased significantly when HIV infected } \\
\text { children included }\end{array}$ \\
\hline Edwards et al. [47] & 2007 & $\begin{array}{l}\text { Democratic Republic } \\
\text { of Congo }\end{array}$ & 91 & $46 \%$ & $\begin{array}{l}\text { Out of } 8 \text { scoring systems analyzed, } 3 / 8 \\
\text { systems did not recommend treatment in } \\
14 \% \text { of HIV-infected children compared } \\
\text { to } 2 \% \text { of noninfected children. Mean } \\
\text { score tended to be higher for HIV-infected } \\
\text { children, but only significant for Edwards } \\
\text { score }\end{array}$ \\
\hline Viani et al. [8] & 2008 & Mexico & 13 & $100 \%$ & $\begin{array}{l}\text { Applied Stegen-Toledo criteria retrospec- } \\
\text { tively but without culture results: } 77 \% \text { had } \\
\text { highly probable } \mathrm{TB}, 15 \% \text { probable, and } \\
8 \% \text { suspicion of TB }\end{array}$ \\
\hline Pedrozo et al. [23] & 2009 & Brazil & 239 & $5 \%$ & $\begin{array}{l}\text { Analyzed scoring system by looking at } \\
\text { median scores of various groups: median } \\
\text { score of } 3 \mathrm{a}(\mathrm{TB}+, \mathrm{HIV}-\text { ) and } 3 \mathrm{~b}(\mathrm{~TB}+\text {, } \\
\text { HIV+) sig. higher than TB negative } \\
\text { groups, median score of TB }+ \text { groups also } \\
\text { was higher than the cutoff of } 30\end{array}$ \\
\hline
\end{tabular}

PPV: positive predictive value.

\section{Discussion}

We identified and reviewed forty different studies of twentytwo unique scoring systems or diagnostic criteria that were developed from five original scoring systems and five original diagnostic criteria. These diagnostic approaches varied in the types of clinical signs and symptoms included in the criteria, the inclusion or exclusion of laboratory testing, and even their diagnostic focus (i.e., pulmonary TB alone or pulmonary and extrapulmonary TB). Studies designed to validate the various diagnostic systems varied significantly in the gold standard chosen for comparison. Because the publication dates of the articles range over the last fifty years, some criteria were developed and evaluated prior to the HIV epidemic, while other studies focused specifically on coinfected children.

The gold standards chosen to evaluate the validity of these diagnostic strategies also varied widely. Cultures can be difficult to obtain in children. Because tuberculous disease in children is often pauci-bacillary, the diagnostic yield of cultures in children is often poor. Although one study used culture as the gold standard [25], others used positive response to treatment [13], CXR [35], or a previous scoring criteria [30]. The most common gold standard was clinical diagnosis. Interestingly, in a study of the ALS assay for diagnosing active TB disease, the assay actually correlated better with clinical diagnosis than either the Kenneth Jones or Keith Edwards scoring criteria [49]. Unfortunately, clinical diagnosis is likely to depend strongly upon the experience and knowledge base of the clinician and thus may be less reliable in settings where clinicians have less training. To allow for comparison of criteria across different studies and settings, future studies need to employ a more consistent gold standard. Ideally, this would be culture-based, as this is a standard for validation that could be reliably replicated across settings. However, because cultures are difficult to obtain in resource-limited settings and can lead to a delay in treatment, performing studies with culture as the gold standard can be difficult.

In addition to using a variety of gold standards, the various studies often included very different sample populations. Some studies did not clearly describe the characteristics of the patient population or how they were selected. Many were retrospective, often utilizing chart review. Ideally, prospective studies of diagnostic systems would evaluate a clearly defined sample of participants with a spectrum of 
disease that is representative of the patients to which the criteria would be applied in clinical practice. It is essential that researchers clearly describe the sample selection process and inclusion criteria in such studies to allow for more accurate comparisons of criteria across different populations or settings and to promote the utility of these systems in clinical practice.

Another challenge in prospective studies of TB diagnosis is the bias that is introduced when, as found in some of these studies, the inclusion or screening criteria for participants often include similar clinical features as the diagnostics systems being evaluated. For example, Pedrozo et al. used history of contact, CXR, and TST result as part of the criteria for inclusion in the study. Chest X-ray and TST were also used as part of their diagnostic gold standard to differentiate latent $\mathrm{TB}$ from no TB from active TB disease. All three inclusion criteria are also used in the Brazil $\mathrm{MOH}$ scoring system being evaluated in this study [25]. This makes it difficult to interpret the accuracy of a diagnostic system and its ability to predict a diagnosis of TB in a particular patient or patient population. This overlap also causes difficulty in determining the relative importance of particular signs or symptoms within the diagnostic system.

The largest shift in the newer diagnostic systems as compared to Kenneth Jones and Keith Edwards is the focus on pulmonary tuberculosis alone. Diagnostic systems focusing simply on pulmonary $\mathrm{TB}$, such as the Brazil $\mathrm{MOH}$ and Marais criteria, have demonstrated higher sensitivities and specificities than those developed to diagnose both extrapulmonary and pulmonary TB. Because children have a higher incidence of extrapulmonary TB [50], using diagnostic systems targeted at pulmonary TB only addresses part of the diagnostic challenge. On the other hand, because TB presents with varied signs and symptoms depending on the site of disease, it is difficult to conceive of a single diagnostic system that could diagnose with high sensitivity and specificity the various types of tuberculosis infections (e.g., vertebral, abdominal, and pulmonary TB). Furthermore, many children with extrapulmonary TB also have pulmonary disease [51]. A new system of classification, focusing on the severity of the disease rather than location, has recently been published and may also be a more reliable and reproducible method. If this is well validated in different settings, it may allow various diagnostic systems to be better compared than is currently possible [52].

At this time, the Brazil MOH scoring system has the most studies evaluating its validity with consistently high sensitivities and specificities. In each of the three studies of this criteria, the scoring system was tested against a slightly different gold standard, ranging from clinical criteria [23, 25] to culture-proven disease [24]. Although this may make some comparisons difficult with the lack of a standard gold standard, the fact that the scoring system holds up fairly well when tested in different ways actually strengthens the evidence for its validity. Though it has not been tested outside of Brazil, it has been tested in both an inpatient [24] and outpatient setting [23, 25]. The performance of the scoring system has also been evaluated in HIV-infected patients. These coinfected children still scored significantly above the cutoff for a diagnosis of TB [23]. All of these evaluations point favorably toward the validity of this scoring system. Evaluating the Brazil MOH scoring system in additional settings worldwide should be an important next step.

The findings of this systematic review are limited by the design and quality of the studies included. The lack of consistent and sometimes clearly defined inclusion criteria among the studies makes it difficult to compare sensitivity and specificity across the different diagnostic systems. Most of the various diagnostic systems have only been evaluated in specific geographic locations or single populations; few studies evaluate a particular diagnostic system in multiple geographic regions or patient populations. Fewer studies have compared the diagnostic yield of multiple criteria in the same patient population. Finally, the increase in the prevalence of HIV during the publication range of these studies makes it difficult to compare studies from thirty years ago to those more recently published. Although this paper includes more than twenty new studies since Hesseling et al. was published in 2002 [21], the number of articles assessing the validity of each diagnostic system is still relatively small. The paper also did not include unpublished data or nonEnglish publications.

\section{Conclusion}

Clinical diagnostic systems in use for many years (e.g., the original Kenneth Jones criteria) and those more recently developed (e.g., the Brazil MOH criteria) have generally been developed, and subsequently adapted, in an attempt to accurately and reliably diagnose tuberculosis in children. As more continues to be learned about the disease and newer, more accurate tests are developed, methods of diagnosis will likely be altered further. It remains crucial that these methods remain applicable to resource-limited settings where the majority of children with TB are still most likely to be found. Although the studies included in this paper are heterogeneous and difficult to compare, the Brazil $\mathrm{MOH}$ criteria seems to emerge as the best validated in children with $\mathrm{TB}$ alone as well as those coinfected with $\mathrm{TB}$ and HIV. Due to the difficulty with obtaining cultures and the expense of the newer diagnostic tests, clinical scoring systems and diagnostic criteria will likely continue to be necessary in resource-limited settings for some time. However, unless additional studies identify refined diagnostic systems with improved sensitivity and specificity, they will likely mainly be utilized as initial screening tools or adjuncts to support clinical diagnosis. Improving the accuracy of diagnosis of pediatric TB is needed to ensure appropriate and timely treatment of those with active disease and to prevent unnecessary morbidity and mortality. Validated clinical diagnostic systems that can be implemented in resource limited settings can improve the accuracy and timeliness of tuberculosis in children; however, additional well-designed studies are needed to validate the accuracy and reliability of current scoring systems and diagnostic criteria. 


\section{References}

[1] D. Maher, "Guidance for National Tuberculosis Programmes on the management of tuberculosis in children. Chapter 1: introduction and diagnosis of tuberculosis in children," International Journal of Tuberculosis and Lung Disease, vol. 10, no. 10, pp. 1091-1097, 2006.

[2] B. J. Marais, R. P. Gie, C. C. Obihara, A. C. Hesseling, H. S. Schaaf, and N. Beyers, "Well defined symptoms are of value in the diagnosis of childhood pulmonary tuberculosis," Archives of Disease in Childhood, vol. 90, no. 11, pp. 1162-1165, 2005.

[3] G. H. Swingler, G. Du Toit, S. Andronikou, L. Van Der Merwe, and H. J. Zar, "Diagnostic accuracy of chest radiography in detecting mediastinal lymphadenopathy in suspected pulmonary tuberculosis," Archives of Disease in Childhood, vol. 90, no. 11, pp. 1153-1156, 2005.

[4] P. B. Fourie, J. P. Swanevelder, and J. Lancaster, "Diagnostic efficiency of the disposable Monotest in detecting tuberculosis infection by setting objective-specific cut-off points for positivity," South African Medical Journal, vol. 86, no. 2, pp. 151154, 1996.

[5] L. M. D. Almeida, M. A. Barbieri, A. C. Da Paixão, and L. E. Cuevas, "Use of purified protein derivative to assess the risk of infection in children in close contact with adults with tuberculosis in a population with high Calmette-Guérin bacillus coverage," Pediatric Infectious Disease Journal, vol. 20, no. 11, pp. 1061-1065, 2001.

[6] B. J. Marais and M. Pai, "Recent advances in the diagnosis of childhood tuberculosis," Archives of Disease in Childhood, vol. 92, no. 5, pp. 446-452, 2007.

[7] G. Stegen, K. Jones, and P. Kaplan, "Criteria for guidance in the diagnosis of tuberculosis," Pediatrics, vol. 43, no. 2, pp. 260 $263,1969$.

[8] R. M. Viani, G. Lopez, E. Chacón-Cruz, P. Hubbard, and S. A. Spector, "Poor outcome is associated with delayed tuberculosis diagnosis in HIV-infected children in Baja California, Mexico," International Journal of Tuberculosis and Lung Disease, vol. 12, no. 4, pp. 411-416, 2008.

[9] H. C. Mathur, S. Saxena, and R. M. Bhardwaj, "Evaluation of Kenneth Jones' criteria for diagnosis of childhood tuberculosis," Indian Journal of Pediatrics, vol. 41, no. 322, pp. 349-355, 1974.

[10] P. Madhavachandran Nair and E. Philip, "A scoring system for the diagnosis of tuberculosis in children," Indian Pediatrics, vol. 18 , no. 5, pp. 299-303, 1981.

[11] V. Seth, "Diagnosis and treatment of tuberculosis: an overview," in Tuberculosis in Children, V. Seth, Ed., pp. 8-19, Indian Academy of Paediatrics, New Delhi, India, 1991.

[12] P. R. Shah, B. Ramakrishna, D. K. Mehta, and R. C. Shah, "Pulmonary tuberculosis in ahmedabad: epidemiology, diagnosis and short course chemotherapy," The Indian Journal of Pediatrics, vol. 59, no. 4, pp. 435-442, 1992.

[13] A. Mehnaz and F. Arif, "Applicability of scoring chart in the early detection of tuberculosis in children," Journal of the College of Physicians and Surgeons Pakistan, vol. 15, no. 9, pp. 543-546, 2005.

[14] R. A. Oberhelman, G. Soto-Castellares, L. Caviedes et al., "Improved recovery of Mycobacterium tuberculosis from children using the microscopic observation drug susceptibility method," Pediatrics, vol. 118, no. 1, pp. e100-e106, 2006.

[15] K. Edwards, "The diagnosis of childhood tuberculosis," Papua and New Guinea Medical Journal, vol. 30, no. 2, pp. 169-178, 1987.
[16] H. J. van Beekhuizen, "Tuberculosis score chart in children in Aitape, Papua New Guinea," Tropical Doctor, vol. 28, no. 3, pp. 155-160, 1998.

[17] M. M. Weismuller, S. M. Graham, N. J. M. Claessens, S. Meijnen, F. M. Salaniponi, and A. D. Harries, "Diagnosis of childhood tuberculosis in Malawi: an audit of hospital practice," International Journal of Tuberculosis and Lung Disease, vol. 6, no. 5, pp. 432-438, 2002.

[18] P. van Rheenen, "The use of the paediatric tuberculosis score chart in an HIV-endemic area," Tropical Medicine and International Health, vol. 7, no. 5, pp. 435-441, 2002.

[19] S. Narayan, S. Mahadevan, and V. T. Serane, "Keith Edwards score for diagnosis of tuberculosis," Indian Journal of Pediatrics, vol. 70, no. 6, pp. 467-469, 2003.

[20] World Health Organization, "Provisional guidelines for the diagnosis and classification of the EPI target diseases for primary health care, surveillance, and special studies," Tech. Rep. EPI/GEN/83/4, World Health Organization, Geneva, Switzerland, 1983.

[21] A. C. Hesseling, H. S. Schaaf, R. P. Gie, J. R. Starke, and N. Beyers, "A critical review of diagnostic approaches used in the diagnosis of childhood tuberculosis," International Journal of Tuberculosis and Lung Disease, vol. 6, no. 12, pp. 1038-1045, 2002.

[22] World Health Organization, Antiretroviral Therapy for HIV Infection in Infants and Children: Towards Universal Access, World Health Organization, Geneva, Switzerland, 2010.

[23] C. Pedrozo, C. Sant'Anna, M. De Fátima March, and S. Lucena, "Clinical scoring system for paediatric tuberculosis in HIV-infected and non-infected children in Rio de Janeiro," International Journal of Tuberculosis and Lung Disease, vol. 13, no. 3, pp. 413-415, 2009.

[24] C. C. Sant'Anna, C. T. S. Orfaliais, M. F. P. De March, and M. B. Conde, "Evaluation of a proposed diagnostic scoring system for pulmonary tuberculosis in Brazilian children," International Journal of Tuberculosis and Lung Disease, vol. 10, no. 4, pp. 463-465, 2006.

[25] C. C. Sant'Anna, M. A. Santos, and R. Franco, "Diagnosis of pulmonary tuberculosis by score system in children and adolescents: a trial in a reference center in Bahia, Brazil," The Brazilian Journal of Infectious Diseases, vol. 8, no. 4, pp. 305310, 2004.

[26] B. J. Marais, R. P. Gie, A. C. Hesseling et al., "A refined symptom-based approach to diagnose pulmonary tuberculosis in children," Pediatrics, vol. 118, no. 5, pp. e1350-e1359, 2006.

[27] P. B. Fourie, P. J. Becker, F. Festenstein et al., "Procedures for developing a simple scoring method based on unsophisticated criteria for screening children for tuberculosis," International Journal of Tuberculosis and Lung Disease, vol. 2, no. 2, pp. 116123, 1998.

[28] N. J. Bergman, "A "treatment score" for primary and pulmonary tuberculosis," Central African Journal of Medicine, vol. 41, no. 1, pp. 1-6, 1995.

[29] Y. Ghidey and D. Habte, "Tuberculosis in childhood: an analysis of 412 cases," Ethiopian Medical Journal, vol. 21, no. 3, pp. 161-167, 1983.

[30] G. B. Migliori, A. Borghesi, P. Rossanigo et al., "Proposal of an improved score method for the diagnosis of pulmonary tuberculosis in childhood in developing countries," Tubercle and Lung Disease, vol. 73, no. 3, pp. 145-149, 1992.

[31] S. A. Madhi, G. E. Gray, R. E. Huebner, G. Sherman, D. Mckinnon, and J. M. Pettifor, "Correlation between CD4+ lymphocyte counts, concurrent antigen skin test and tuberculin 
skin test reactivity in human immunodeficiency virus type 1infected and -uninfected children with tuberculosis," Pediatric Infectious Disease Journal, vol. 18, no. 9, pp. 800-805, 1999.

[32] G. E. Salazar, T. L. Schmitz, R. Cama et al., "Pulmonary tuberculosis in children in a developing country," Pediatrics, vol. 108, no. 2, pp. 448-453, 2001.

[33] D. B. Cundall, "The diagnosis of pulmonary tuberculosis in malnourished Kenyan children," Annals of Tropical Paediatrics, vol. 6, no. 4, pp. 249-255, 1986.

[34] A. P. Stoltz, P. R. Donald, P. M. Strebel, and J. M. T. Talent, "Criteria for the notification of childhood tuberculosis in a high-incidence area of the western Cape Province," South African Medical Journal, vol. 77, no. 8, pp. 385-386, 1990.

[35] N. Beyers, R. P. Gie, H. S. Schaaf et al., "Delay in the diagnosis, notification and initiation of treatment and compliance in children with tuberculosis," Tubercle and Lung Disease, vol. 75, no. 4, pp. 260-265, 1994.

[36] R. P. Gie, N. Beyers, H. S. Schaaf et al., "TB or not TB? An evaluation of children with an incorrect initial diagnosis of pulmonary tuberculosis," South African Medical Journal, vol. 85, no. 7, pp. 658-662, 1995.

[37] H. S. Schaaf, N. Beyers, R. P. Gie et al., "Respiratory tuberculosis in childhood: the diagnostic value of clinical features and special investigations," Pediatric Infectious Disease Journal, vol. 14, no. 3, pp. 189-194, 1995.

[38] K. A. F. Houwert, P. A. Borggreven, H. S. Schaaf, E. Nel, P. R. Donald, and J. Stolk, "Prospective evaluation of World Health Organization criteria to assist diagnosis of tuberculosis in children," European Respiratory Journal, vol. 11, no. 5, pp. 1116-1120, 1998.

[39] I. B. Palme, B. Gudetta, J. Bruchfeld, L. Muhe, and J. Giesecke, "Impact of human immunodeficiency virus 1 infection on clinical presentation, treatment outcome and survival in a cohort of Ethiopian children with tuberculosis," Pediatric Infectious Disease Journal, vol. 21, no. 11, pp. 1053-1061, 2002.

[40] A. C. Theart, B. J. Marais, R. P. Gie, A. C. Hesseling, and N. Beyers, "Criteria used for the diagnosis of childhood tuberculosis at primary health care level in a high-burden, urban setting," International Journal of Tuberculosis and Lung Disease, vol. 9, no. 11, pp. 1210-1214, 2005.

[41] J. M. Cohen, E. Whittaker, S. Walters, H. Lyall, G. TudorWilliams, and B. Kampmann, "Presentation, diagnosis and management of tuberculosis in HIV-infected children in the UK," HIV Medicine, vol. 9, no. 5, pp. 277-284, 2008.

[42] J. Kiwanuka, S. M. Graham, J. B. S. Coulter et al., "Diagnosis of pulmonary tuberculosis in children in an HIV-endemic area, Malawi," Annals of Tropical Paediatrics, vol. 21, no. 1, pp. 5-14, 2001.

[43] C. M. Osborne, "The challenge of diagnosing childhood tuberculosis in a developing country," Archives of Disease in Childhood, vol. 72, no. 4, pp. 369-374, 1995.

[44] P. M. Jeena, T. Mitha, S. Bamber, A. Wesley, A. Coutsoudis, and H. M. Coovadia, "Effects of the human immunodeficiency virus on tuberculosis in children," Tubercle and Lung Disease, vol. 77, no. 5, pp. 437-443, 1996.

[45] R. S. Ramachandran, "Tuberculosis in children: experience with 1284 cases," Indian Pediatrics, vol. 5, no. 12, pp. 564-571, 1968.

[46] A. C. Hesseling and R. P. Gie, "Scoring systems for the diagnosis of childhood tuberculosis: are we making progress?" International Journal of Tuberculosis and Lung Disease, vol. 11, no. 3, p. 245, 2007.

[47] D. J. Edwards, F. Kitetele, and A. Van Rie, "Agreement between clinical scoring systems used for the diagnosis of pediatric tuberculosis in the HIV era," International Journal of Tuberculosis and Lung Disease, vol. 11, no. 3, pp. 263-269, 2007.

[48] T. Ahmed, F. Sobhan, A. M. S. Ahmed et al., "Childhood tuberculosis: a review of epidemiology, diagnosis, and management," Infectious Diseases Journal of Pakistan, vol. 17, no. 2, pp. 52-60, 2008.

[49] R. Raqib, D. Mondal, M. A. Karim et al., "Detection of antibodies secreted from circulating Mycobacterium tuberculosisspecific plasma cells in the diagnosis of Pediatric tuberculosis," Clinical and Vaccine Immunology, vol. 16, no. 4, pp. 521-527, 2009.

[50] A. Kumar, S. Upadhyay, and G. Kumari, "Clinical presentation, treatment outcome and survival among the HIV infected children with culture confirmed tuberculosis," Current HIV Research, vol. 5, no. 5, pp. 499-504, 2007.

[51] H. S. Schaaf, B. J. Marais, A. Whitelaw et al., "Cultureconfirmed childhood tuberculosis in Cape Town, South Africa: a review of 596 cases," BMC Infectious Diseases, vol. 7, article 140, 2007.

[52] C. A. Wiseman, R. P. Gie, J. R. Starke et al., "A proposed comprehensive classification of tuberculosis disease severity in children," Pediatric Infectious Disease Journal, vol. 31, no. 4, pp. 347-352, 2012. 


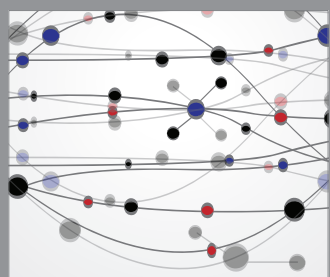

The Scientific World Journal
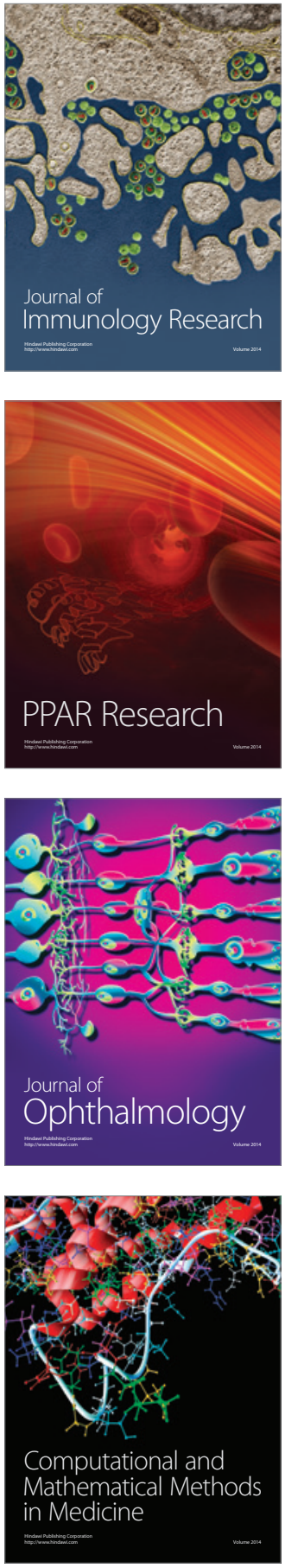

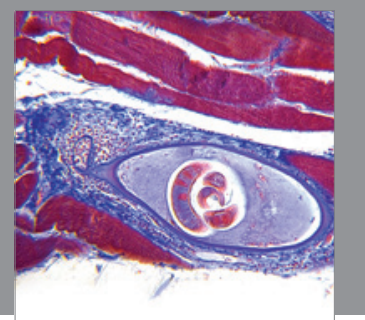

Gastroenterology

Research and Practice
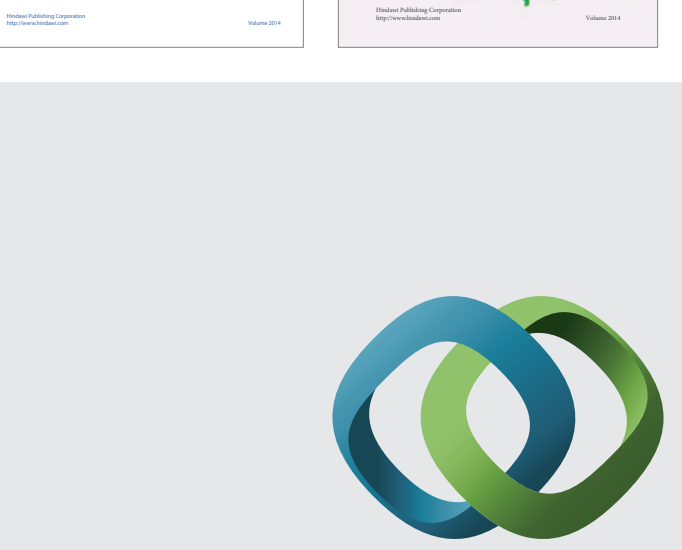

\section{Hindawi}

Submit your manuscripts at

http://www.hindawi.com
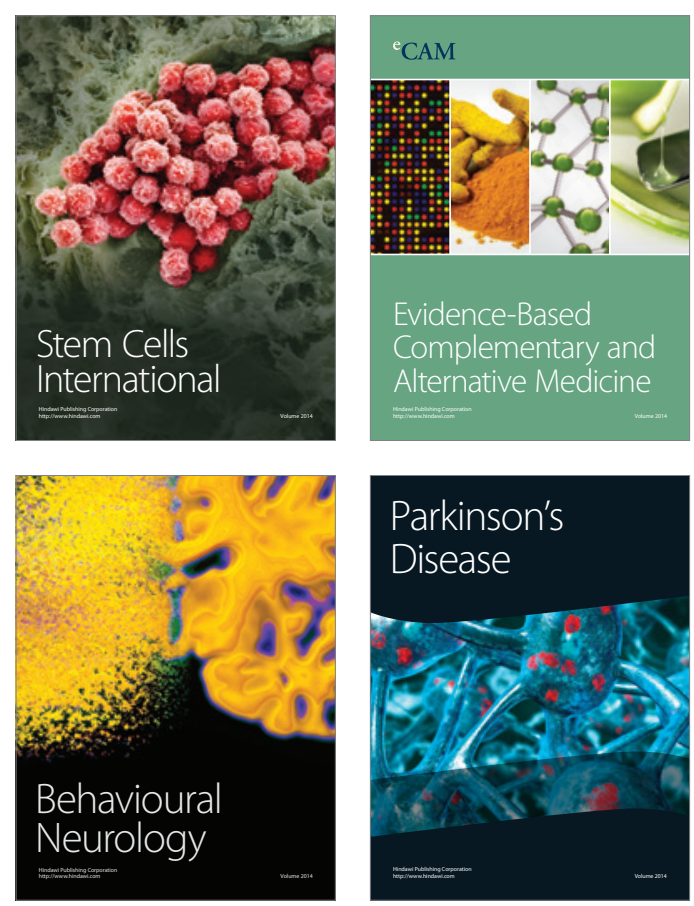

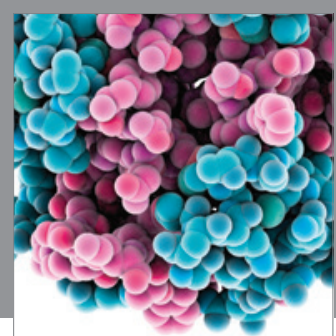

Journal of
Diabetes Research

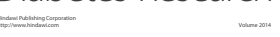

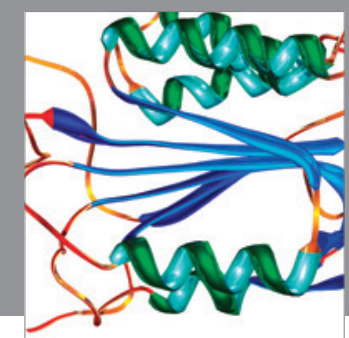

Disease Markers
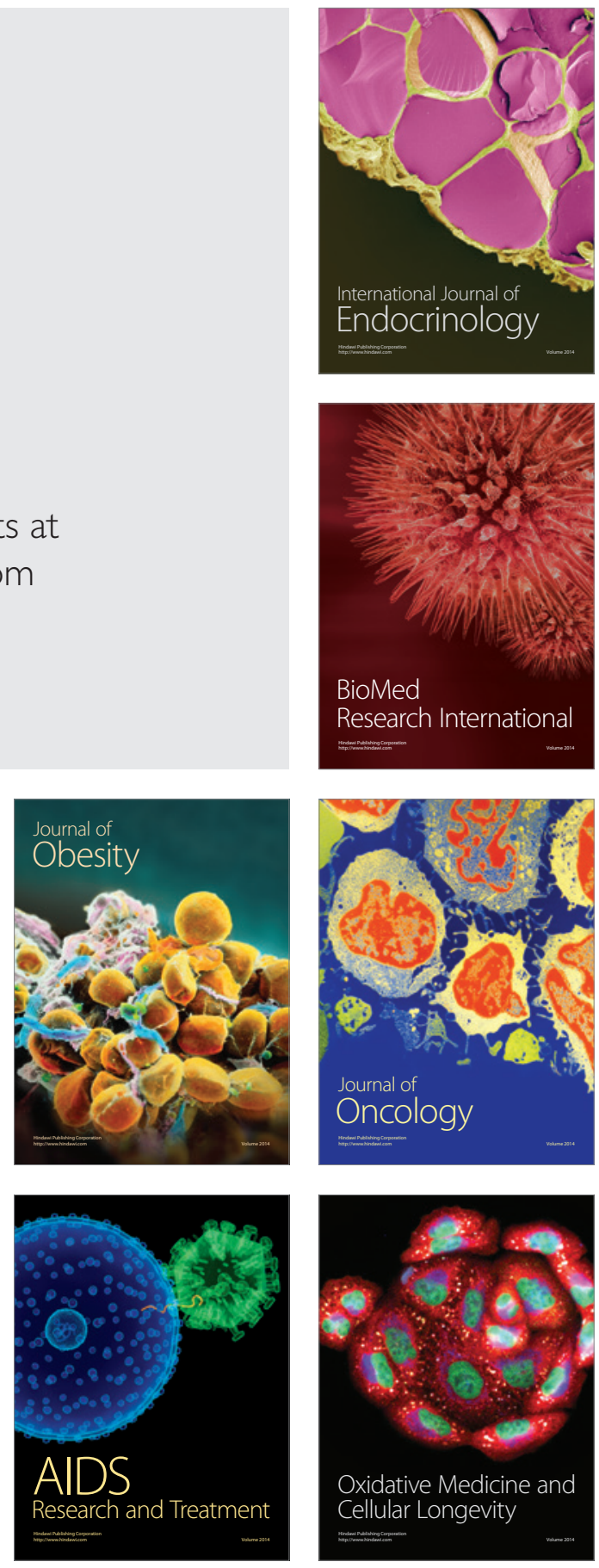